\title{
Short communication: Diversity of tropical plants and their attractant properties for subterranean termite Coptotermes curvignathus
}

\author{
YULIATI INDRAYANI ${ }^{1, \varphi}$, MUSRIZAL MUIN ${ }^{2, ~}$, , TSUYOSHI YOSHIMURA ${ }^{3, m}$ \\ ${ }^{1}$ Faculty of Forestry, Universitas Tanjungpura. J1. Imam Bonjol Pontianak 78124, West Kalimantan, Indonesia. Tel./Fax. +62-561-767673, \\ 'email: mandaupermai@yahoo.com \\ ${ }^{2}$ Faculty of Forestry, Universitas Hasanuddin. Jl. Perintis Kemerdekaan km 10, Makasar 90245, South Sulawesi, Indonesia. \\ wemail: musrizal@unhas.ac.id \\ ${ }^{3}$ Research Institute for Sustainable Humanosphere, Kyoto University. Gokasho, Uji, Kyoto 611-0011, Japan. ${ }^{\mathbf{m}}$ email: tsuyoshi@ rish.kyoto-u.ac.jp
}

Manuscript received: 30 April 2017. Revision accepted: 26 August 2017.

\begin{abstract}
Indrayani Y, Muin M, Yoshimura T. 2017. Short communication: Diversity of tropical plants and their attractant properties for subterranean termite Coptotermes curvignathus. Biodiversitas 18: 1353-1357. The effectiveness of bio-based attractant from different leaves of tropical plants on subterranean termites Coptotermes curvignathus was examined under laboratory conditions. Five kinds of leaves of tropical plant such as cajuput (Melaleuca leucadendron L.), cinnamon (Cinnamomum burmannii (Nees \& Th. Nees) Nees ex Blume, clove (Syzygium aromaticum (L.) Merr. \& L.M. Perry), bay (Syzygium polyanthum Wight) and basil (Ocimum sanctum L.) were serving as termite feeding bio-based attractants for $C$. curvignathus. Bio-based attractants were obtained by cross cut dry leaves into smaller particles (dry weight $200 \mathrm{~g}$ ) and dipped in $70 \%$ ethanol solution for 3 x $24 \mathrm{hrs}$. The extracts were then subjected to a rotary evaporator at $60{ }^{\circ} \mathrm{C}$ until the extract changed to gel condition. 50 workers and five soldiers of $C$. curvignathus were tested in a no-choice test bioassay to determine their preferred bio-based attractant under the concentration of $10 \%$ and $50 \%$. No-choice bioassays chambers were assembled by connecting two clear plastic glasses (bottom diameter $5 \mathrm{~cm}$, top diameter $7 \mathrm{~cm}$ ) with clear plastic hoses (inner diameter $3 \mathrm{~mm}$, outer diameter $5 \mathrm{~mm}$ ). Clear plastic hoses connectors allowed termites to move freely between glasses. A laboratory bioassay determined that the response of subterranean termite $C$. curvignathus on clove leaf was greater than other five leaves as indicated by termite moving time, and did not differ significantly between concentrations. No direct relationships were noted between the speed of the first termite moving time and number of termites recruited to the bio-attractant chamber.
\end{abstract}

Keywords: Bio-attractant, Coptotermes curvignathus, diversity, subterranean termite, tropical leaves plant

\section{INTRODUCTION}

Subterranean termites are one of the most important termite pests in Indonesia even in the world. Subterranean termites have been found with a widespread global distribution (Henderson 2008; Rust and Su 2012). Methods have been widely used for subterranean termite control, such as bait technologies and liquid termiticides (Henderson, 2001). Liquid termiticides for a building are applied by drilling holes into the walls and slabs (Rambo 1985). In general, liquid termiticides were categorized into two groups. First is repellent that serves as a barrier between termites in the soil and the structure above ground; second is non-repellent which acts to kill termites upon contact (Gahlhoff and Koehler 2001; Kard 1998, 2000; Thorne and Breisch 2001). However, liquid termiticides have several limitations such as (i) it only affects termite population that is located in the treated areas, (ii) termites exposed to the non-repellent termiticides might die before returning to its nest to spread the toxicant to other nest mates (Forschler 1994; Su and Scheffrahn 1988, 1990; Su et al. 1993), (iii) the active ingredients in liquid termiticides will be degraded over time in soil and have to be reapplied (Mauldin et al. 1987).
Although liquid termiticides application is still the most widely used method for subterranean termite control, new methodologies are required to overcome some of their limitations. One of those new methodologies has been the termite bait systems. The main concept of bait system is the slow killing action property of the toxicant in affecting the termites. These bait systems are designed to allow the worker termites to feed the toxicant and live long enough to return to the nest to spread it to other nest members (Dow AgroSciences 1999).

Like liquid termiticides, bait systems also have their limitations. One of those limitations is the presence of competing for food resources. Termites have many food resources in the field, such as building structures or natural food sources. If natural food sources are more attractive than the bait, termites might not be recruited to the bait. As Waller et al. (1999) stated that one of the factors affecting termite recruitment is chemical directional cues to the location of the bait, this chemical is known as an attractant. Therefore, it is indispensable to find proper attractive food sources for bait matrix. Termite colony depend on worker termites for its food supply. Thus, a bait should be formulated with an attractant to recruit the worker termites as much as possible to the bait. 
In principle, termite will follow a concentration gradient of the attractant material to find food sources in the bait matrix. So far, attractants utilized in the bait system consist of synthetic chemicals, and there has been no report on the effect of synthetic attractants to the environment. Thus, we think it is necessary to develop a bio-based attractant from nature. From this study, we hope to develop a technique to ensure termites to locate baits and answer the question on how termites find food sources in nature.

The objective of this research was to investigate the effectiveness of the bio-based attractant from five different leaves of tropical plants on subterranean termite (Coptotermes curvignathus Holmgren, 1913) in the laboratory condition.

\section{MATERIALS AND METHODS}

\section{Termites}

A number of 50 workers and five soldiers subterranean termites were obtained from secondary forest, Pontianak, West Kalimantan, Indonesia in June 2016. Termites were maintained in the plastic chamber with rubber wood (Hevea brasiliensis) at $28-30^{\circ} \mathrm{C}$ and $70-80 \%$ relative humidity for one month before used in the bioassay. Only healthy termites used for experiments.

\section{Attractant preparation}

Five kinds of leaves, cajuput leaf, cinnamon leaf, clove leaf, bay leaf and basil leaf were collected from an area in Pontianak City, West Kalimantan, Indonesia in March-April 2016. Before being used in experiment, the leaves were air dried inside a room for three days. Dry leaves were then cross cut into smaller particles (with a total dry weight of $200 \mathrm{~g}$ ) and dipped in $70 \%$ ethanol solution for $3 \times 24 \mathrm{hrs}$. The extracts were then subjected to a rotary evaporator at $60{ }^{\circ} \mathrm{C}$ until the extract changed to gel condition.

\section{Termite bioassay}

\section{Bioassay chambers}

Consumption bioassays were performed in no-choice bioassays chambers. Tests chamber was used to evaluate termite moving time and number of termites recruited to bio-attractants upon the presence of a competing food source.

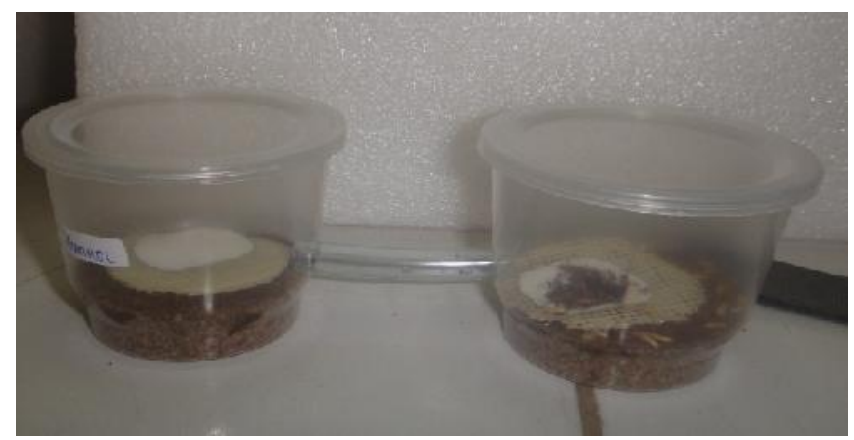

Figure 1. No choice-test bioassay

\section{No-choice bioassay}

No-choice bioassays chambers were assembled by connecting two clear plastic cups (bottom diameter $5 \mathrm{~cm}$, top diameter $7 \mathrm{~cm}$ ) with a clear plastic hose (inner diameter $3 \mathrm{~mm}$, outer diameter $5 \mathrm{~mm}$ ). The plastic hose acts as a connector that allowed termites to move freely between glasses. Both plastic cups were filled with $50 \mathrm{~g}$ moist sand, and the surface of the sand was covered with a plastic sheet (Figure 1).

A sheet of cellulose paper with a diameter of $4 \mathrm{~cm}$ containing an attractant (concentration of $10 \%$ and 50\%) was placed on top of the sand substrate in one of the plastic cups, while a same size cellulose paper that was added with distilled water was put on the sand substrate in the other plastic cup. In each experiment, 50 workers and five soldiers of $C$. curvignathus were subjected into the plastic cup containing the sheet of cellulose paper with distilled water. Termite moving activities were then monitored for 8 hours. Bait efficacy is determined by the number of termites that are moving to the attractant-supplemented cellulose paper. Each treatment consisted of three replicates.

\section{Identification of chemical components using GC-MS}

Five leaves crude extract was analyzed using a Shimadzu Gas Chromatography-Mass Spectrometry (GC-MS-QP2010) with a Flame Ionization Detector (FID) using fused silica capillary column type phase Rtx-5MS (60 m by $0.25 \mathrm{~mm}$ ID) with helium as carrier gas at a flow rate of $0.85 \mathrm{~mL}$ per minute. The column temperature was programmed initially at $50^{\circ} \mathrm{C}$ for $10 \mathrm{~min}$, then increased $3^{\circ} \mathrm{C}$ per minute to $280^{\circ} \mathrm{C}$ and was kept isothermally for $1 \mathrm{~min}$. The temperature of injector port and interface of mass spectrometry (MS) was $280^{\circ} \mathrm{C}$. The total ion chromatogram obtained as auto integrated by Chemstation software and the compounds were identified by comparison with Wiley $9^{\text {th }}$ edition NIST 11 Mass Spectral Library (Indrayani et al. 2016).

\section{Data analysis}

Data were statistically analyzed by Variable Analysis in a factorial design, and Tukey Analysis was used for comparison of the mean values (Gaspersz 1994).

\section{RESULTS AND DISCUSSION}

\section{Termite moving time}

In this experiment, a significantly faster termite movement to the bio-based attractant chamber was noted in both clove leaf treatment concentration (10\% and 50\%), which were under 1.5 minutes. The termite movement time in the clove leaf treatment was significantly lesser than that of all other leaves (Tukey's test: $P<0.05$ ) (Figure 2). In treatments other than clove leaf, the termite moving moment was noted after 7 to 14 minutes for the concentration of $10 \%$ and 4 to 11 minutes for the concentration of $50 \%$, except that of the cinnamon leaf treatment which was at 1.58 minutes. There were also significantly lesser moving times of termites in the concentration of $50 \%$ than that in the concentration of $10 \%$ 
for all kind of leaves except for clove leaf (Tukey's test: $P$ $<0.05)$. The least moving time of termite observed in the clove leaf treatment was presumably because clove leaf contains a higher level of eugenol among the five leaves. Eugenol has been reported to successfully recruit fruit flies (Stark et al. 2000). GC-MS analysis showed relative percentage $(\%)$ of eugenol compound in each leaf extracts used in this study: clove leaf $7.92 \%$, cinnamon leaf $4.64 \%$, cajuput leaf $3.36 \%$, basil leaf $2.24 \%$ and bay leaf $0 \%$ (Figure 4.A-E). GC-MS analysis results of the clove and cajuput leaves in this experiment were the same as those in the previous experiment (Indrayani et al. 2016). Consistent with its zero-eugenol content, basil leaf showing the latest termite moving time of all leaf extract treatment which was after 14 minutes. Control treatment in this study, i.e. without any bio-attractant addition, showed the slowest termite moving time (108.47 minutes).

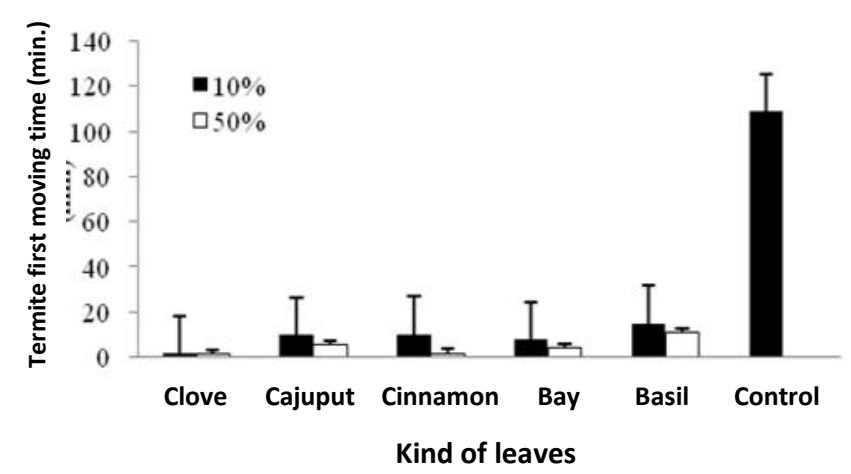

Figure 2. Termite first moving time (minutes) entering attractant chamber

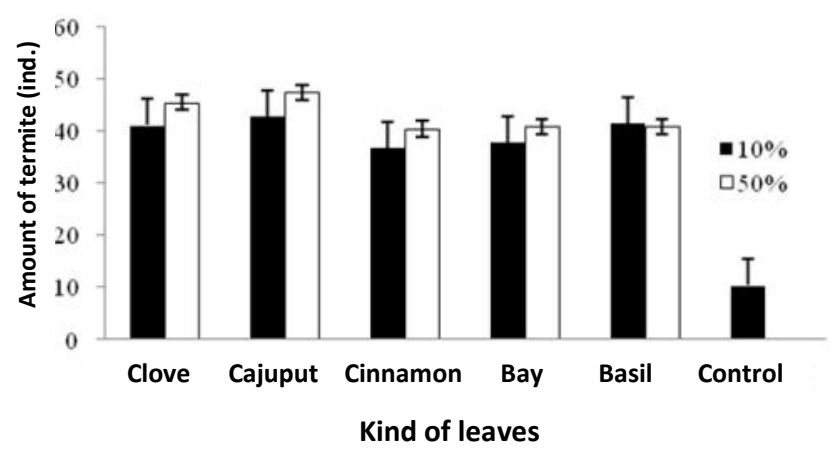

Figure 3. Number of termite entering attractant chamber after 8 hours observation

\section{Number of termites entering attractant chamber}

Our study showed that there was no significant difference in the number of termites recruited to the attractant chamber in all leaves treatment for both concentrations of $10 \%$ and $50 \%$ (Tukey's test: $P<0.05$ ). This result indicates that there is no direct relationships between termite moving time and the number of termites recruited in bio-based attractants. Figure 3 illustrates the number of termites accumulated inside the attractants chambers after 8 hours observation. From the initial amount of 50 worker termites introduced into the starting chamber, the average numbers of termites found to be recruited to the leaf-based attractant chambers was approximately 40 individuals at the concentration of $10 \%$ and about 43 individuals at the concentration of $50 \%$. As a reference, the number of termites that moved towards the control chamber containing a sheet of cellulose paper with distilled water was only about 10 individual termites.

These results revealed that termites could detect chemicals in the substrates and move towards chambers containing bio-based attractants. Furthermore, these results also indicated that eugenol compounds in the leaf extracts have the potential to attract termites to find the bait matrix. These results are similar to those reported by Waller et al. (1999) in which a greater number of worker termites was recruited to chambers containing sucrose and yeast than those that remained in the water chamber. A similar finding was also found by Sajap et al. (2005) who worked with noviflumuron as the bait active ingredient to attract Coptotermes gestroy.

In conclusion, this study highlights that extracts of plant leaf used as bio-based attractants for termite $C$. curvignathus were found to be effective in the laboratory test. Laboratory bioassay showed that among the five plant leaves observed in this study, the greatest response of the subterranean termite regarding their first moving time could be found on clove leaf-based attractants, regardless of the attractant concentrations. In addition, no direct relationships were noted between the speed of termite moving time and the number of termites located in biobased attractants. Further works are still required, in particular, concerning the effectiveness of eugenol as an attractive compound for the development of a termite bait system.

\section{ACKNOWLEDGEMENTS}

The authors gratefully acknowledge Directorate General of Higher Education of Indonesia for financial support in Fiscal Year 2015 under "International Research Collaboration and Scientific Publication" program, and the DOL/LSF Collaborative Research Program at Research Institute for Sustainable Humanosphere (RISH), Kyoto University, Japan. 

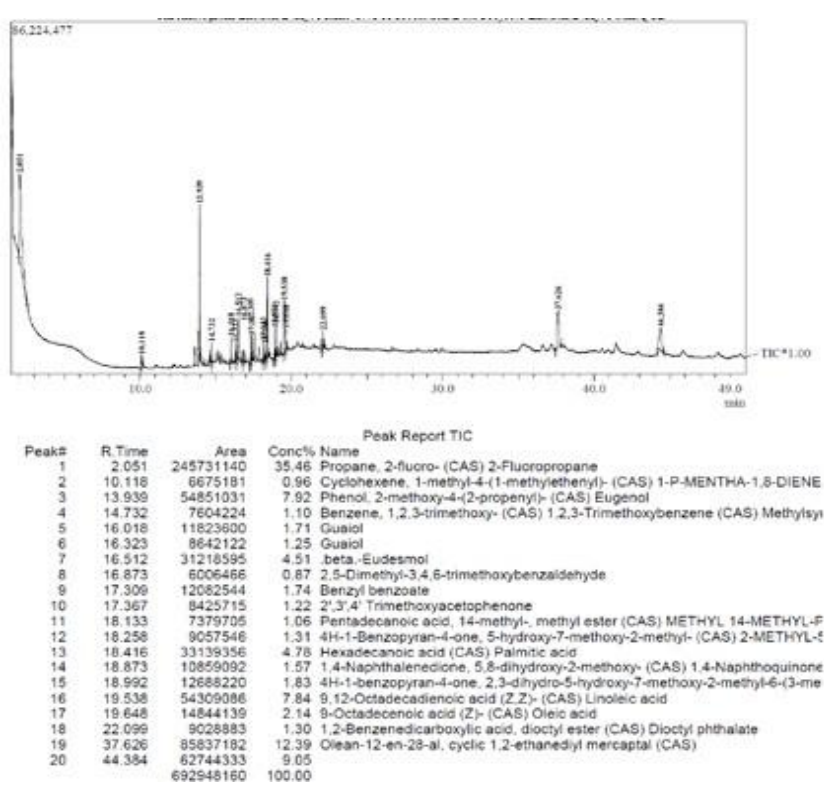

Figure 4.A. GC-MS analysis result of clove leaf

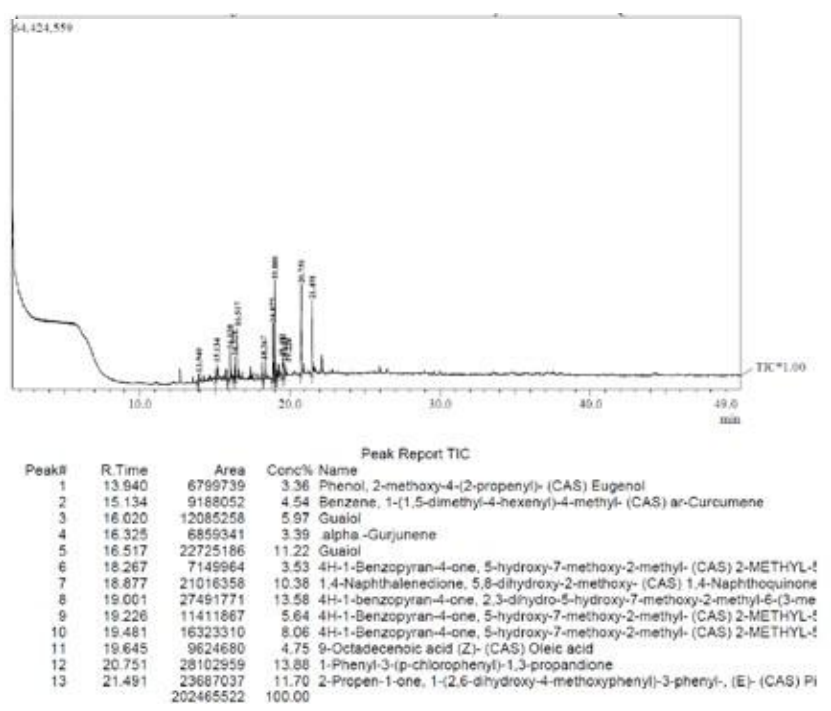

Figure 4.B. GC-MS analysis result of cajuput leaf
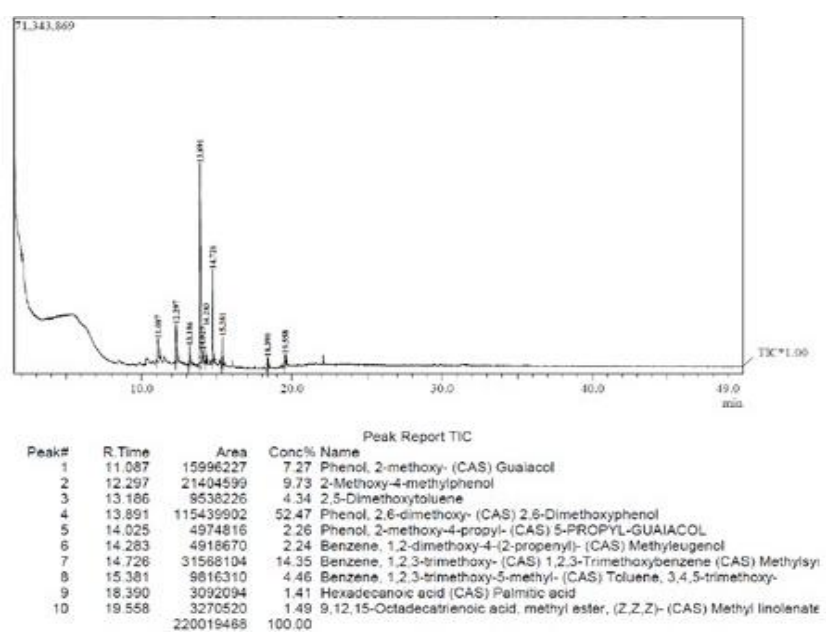

Figure 4.C. GC-MS analysis result of basil leaf

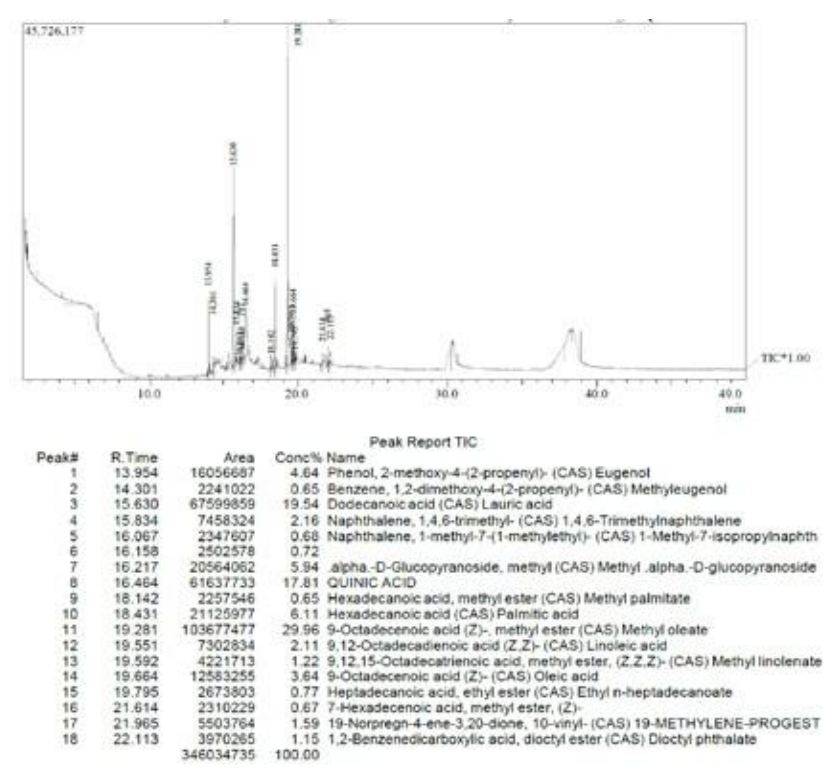

Figure 4.D. GC-MS analysis result of cinnamon leaf

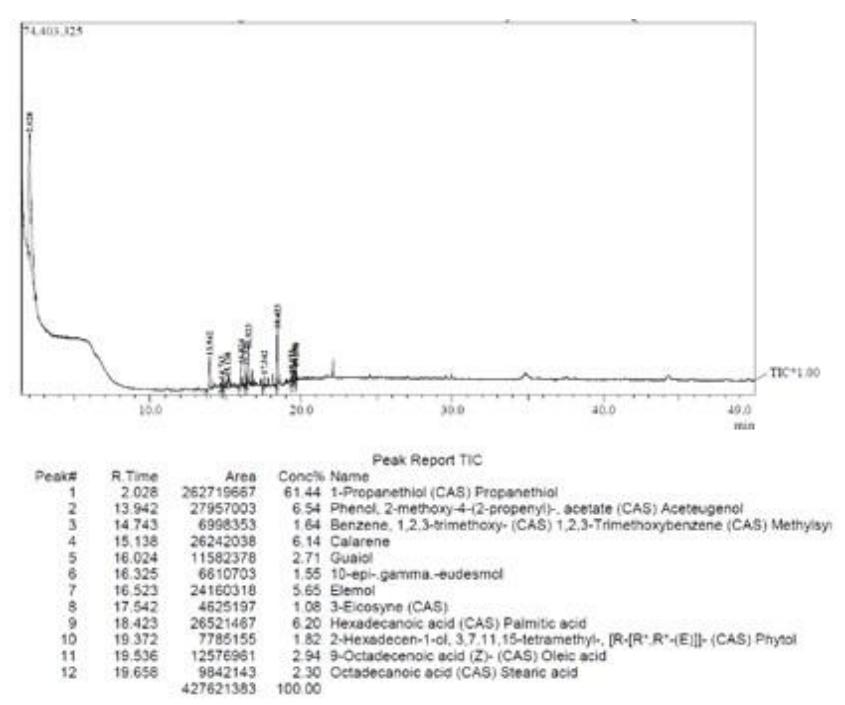

Figure 4.E. GC-MS analysis result of bay leaf

\section{REFERENCES}

Dow AgroSciences. The Sentricon system: protect your home by getting termites where they live. Fact Sheet \#U01-028-051. 1999.

Forschler BT. 1994. Fluorescent spray paint as a topical marker on subterranean termites (Isoptera: Rhinotermitidae). Sociobiology 24: 27-38.

Gahlhoff Jr JE, PG Koehler. 2001. Penetration of the eastern subterranean termite into soil treated at various thicknesses and concentration of Dursban TC and Premise 75. J Econ. Entomol 94: 486-491.

Gaspersz V. 1994. Experimental design method. Armico, Jakarta.

Henderson G. 2001. Practical considerations of the Formosan subterranean termite in Louisiana: a 50-year-old problem. Sociobiology 37: 281-393.

Henderson G. 2008. The termite menace in New Orleans: did they cause the Boodwalls to tumble? Am Entomol 54: 156-162.

Indrayani Y, Muin M, Yoshimura T. 2016. Crude extracts of two different leaf plant species and their responses against subterranean termite Coptotermes formosanus. Nusantara Biosci 8 (2): 226-231. 
Kard B. 1998. Termiticide field tests: Continue moving forward. Pest Control 66: 42-44.

Kard B. 2000. Gulfport study welcomes new entries. Pest Control 68: 38 44.

Mauldin JK, SC Jones, RH Beal. 1987. Soil termiticides: A review of efficacy data from field tests. Proceeding of 18th Annual Meeting of the International Research Group on Wood Preservation-Working Group 1b. Biological Problems. Document IRG/WP/1323. Stockholm, Sweden.

Rambo GW. 1985. Approved reference procedures for subterranean termite control. Natl Pest Control Assoc, Vienna, VA.

Rust MK, NY Su. 2012. Managing social insect of urban importance. Ann Rev Entomol 57: 355-375.

Sajap AS, Lee LC, Ouimette D, Jaafar AM. 2005. Field evaluation of noviflumuron for controlling Asian Subterranean termite, Coptotermes gestroi (Isoptera: Rhinotermitidae). Proceedings of the 5th International Conference on Urban Pests. Perniagaan, Malaysia.

Stark IVJD, Kido MH, Ketter HM, Whitehand LC. 2000. Methyl eugenol and cue-lure traps for suppression of male oriental fruit flies and melon flies (Diptera: Tephiritidae) in Hawaii: Effects of lure mixtures and weathering. J Econ Entomol 93: 81-87.

Su NY, RH.Scheffrahn. 1988. Foraging population and territory of the Formosan subterranean termite (Isoptera: Rhinotermitidae) in an urban environment. Sociobiology 14: 353-359.

Su NY, RH Scheffrahn. 1990. Comparison of eleven soil termiticides against the Formosan subterranean termite and eastern subterranean termite (Isoptera: Rhinotermitidae). J Econ Entomol 83:1918-1924.

Su NY, RH Scheffrahn, PM Ban. 1993. Barrier efficacy of pyrethroid and organophosphate formulations against subterranean termites (Isoptera: Rhinotermitidae). J Econ Entomol 86: 772-776.

Thorne BL, NL Breisch. 2001. Effects of sublethal exposure to imidacloprid on subsequent behavior of subterranean termite Reticulitermes virginicus (Isoptera: Rhinotermitidae). J Econ Entomol 94: 492-498.

Waller DA, Morlino SE, Matkins N.1999. Factors affecting termite recruitment to baits in Laboratory and field studies. Proceedings of the Third International Conference on Urban Pests. Prague, Graficke zavody Hronov, Czech Republic. 